Journal of Advanced Research in Fluid Mechanics and Thermal Sciences

\title{
Numerical Investigation of Heat Transfer in Car Radiation System Using Improved Coolant
}

\author{
Qais Hussein Hassan ${ }^{1,}{ }^{*}$, Shaalan Ghanam Afluq ${ }^{1}$, Mohamed Abed Al Abas Siba ${ }^{2}$ \\ 1 Department of Power Mechanics, Kut Technical Institute, Middle Technical University, Baghdad, Iraq \\ 2 Department of Power Mechanics, Institute of Technology, Middle Technical University, Baghdad, Iraq
}

\section{$\begin{array}{ll}\text { ARTICLE INFO ABSTRACT } & \text { ART }\end{array}$}

Article history:

Received 22 January 2021

Received in revised form 9 April 2021

Accepted 13 April 2021

Available online 22 May 2021

Keywords:

ANSYS; CFD; Radiation system; Heat

transfer; FEM; Nanoparticles

\begin{abstract}
In this study, numerical analysis of heat transfer in the radiation system of the car has been investigated by using pure water and water with nanofluid. ANSYS fluent version 16.1 has been conducted to carry out the simulation process using Computational Fluid Dynamic (FCD) approach. This study has been validated with experimental results and based on the simulation results the error was $8 \%$ when applying the same boundary condition. And the validation process was carried out for the flow rate with Nusselt number in both concertation $0.7 \%$ and $1 \%$. Based on numerical analysis, the Nusselt number has been increased by increasing nano particle concertation. Increased number of Nusselt causes the enactment of the heat exchanger. The previous experimental data show that the heat transfer of the nanofluids was based highly on the concentration of nano particles, the flux conditions and the weak temperature-dependent heat transfer conditions.
\end{abstract}

\section{Introduction}

In recent years, intensive research has been underway on nanofluids (metal or metal oxide parts usually smaller than $100 \mathrm{~nm}$ suspended within a base fluid) and their role in the heat transfer. As a vehicle engine coolant, one major use for nanofluids [1]. The very high surface area of nanoparticles increases thermal conductivity, even at low concentrations. The significant increase in nanofluid thermal properties has attracted scientific interest in recent years. For fluids with suspended nanoparticles [2] first used the word "nanofluid"; these kinds of fluids have been studied by various experiments in different fields. In car radiators, liquid-cooled computers and cold-water air conditioners, the main use of $E G$ is as a tool for convective heat transfer. The combined water and EG were employed because water is a much more safe engine coolant [3]. The problem with water is that it freezes or boils at high temperatures. Anti-freezing agents like EG can tolerate significantly higher temperature extremes, so that we can make a concession with water [4]. Some of the water's

\footnotetext{
* Corresponding author.

E-mail address: qaiahussen@gmail.com
}

https://doi.org/10.37934/arfmts.83.1.6169 
strong freezing properties are preserved, but the anti-freeze benefits from the ability to survive high temperatures.

Leong et al., [5] has performed a 2D numerical study in horizontal counterpower dual pipe thermal exchange of single-phase forced convective heat transfer for $\mathrm{Al}_{2} \mathrm{O}_{3}$ and $\mathrm{TiO}_{2}$ nanofluids. They have reported that by adding nanoparticles to the base fluid, heat transfer improved. Goudarzi and Jamali [6] had hypothesized the continuous heating flow in the laminar tube wall of nanofluid heat transfer modeling CFD within tubes with circular cross sections, in a fully formed environment. Nanoparticles with medium diameters between 45 and $150 \mathrm{~nm}$ at concentrations of 1 percent, 2 percent and 4 percent were used in the single-phase simulation. The results showed differences of up to 10 percent in the experimental data; it was observed that heat transfer increased as the nanoparticles concentration increased.

In several experiments at the Royal Institute of Science, School of Technology and Health (KTHSTH) in Stockholm, heat output from radiators and vertical plates with natural or induced convection has been analytically measured and investigated by CFD simulations. The primary aim was to discover ways of increasing the thermal performance of radiators [7]. It has been found that Sharaf et al., can improve thermal efficiency by enlarging or changing existing radiators or adding convection fins. However, the downside of such improvements has also been higher manufacturing costs. Therefore, emphasis was centered on ways to improve heat production that could be simpler and less effective, such as steering breathing air to heated radiator surfaces or pushing air between radiator panels.

The effect of convective thermal transfer of nanofluids under laminar and turbulent flow regimes was researched experimentally [8]. They used a straight circular cross section for the laminar and turbulent flow regimes of a tube with a constant walled heat flow. Subhedar et al., [9] investigated the results of thermo-physical properties of the models for predicting convective heat transfer coefficients of nanofluids at low concentrations.

They found that the validity and accuracy of the experimental convective heat transfer coefficient at low nanoparticle concentrations of the base fluid relies more on the empirical calibration of the system than on nanofluid thermo-physical versions. The increase in the thermal transfer of nanofluids is based on the turbulent flow of water in a car radiator. Sharaf et al., $[10,11]$ reported heat transfer and hydraulics under constant wall temperature conditions in a horizontal tunnel for $\mathrm{SiO}_{2}$ nanoparticles. Measurements were taken at 20,50 and $70 \mathrm{C}$ and 200 x e10 Reynolds numbers. The study has demonstrated an increase in the convective heat transfer of nanofluids over pure water. This paper conducted a numerical analysis using water-based nano fluid for the automotive radiator. Ansys was used to sample the heat transfer process fluently with CFD.

\section{Materials and Methods}

\subsection{Mechanical Properties of Nanofluid and Materials}

In order to carry out simulation process, physical properties of fluid are required to perform the boundary condition of the previous work. Table 1 show the required information. Nanofluid grain size is $20 \mathrm{~nm}$.

Table 1

Physical properties of the employed fluid

\begin{tabular}{lllll}
\hline$\rho\left(\mathrm{kg} / \mathrm{m}^{3}\right)$ & $\mu(\mathrm{kg} / \mathrm{m} . \mathrm{s})$ & $\mathrm{k}\left(\mathrm{W} / \mathrm{m}^{\circ} \mathrm{C}\right)$ & $\mathrm{Cp}\left(\mathrm{J} / \mathrm{kg} .{ }^{\circ} \mathrm{C}\right)$ & $\alpha\left(\mathrm{m}^{2} / \mathrm{s}\right)$ \\
\hline 992 & 0.00065 & 0.633 & 4174 & $1.5 \times 10^{-7}$ \\
\hline
\end{tabular}




\subsection{Primary Boundary Conditions}

A flow loop was included for the simulation of liquid-side heat transfer conduct in the car radiator. A centrifuge pump with a constant flow rate of 10 Liter per minute is used to flow the test fluid from the feed to the radiator from the five-layer tube ( 0.75 inch in diameter) [12]. The air flow rate was 0.1 per minute with an accuracy of between $45^{\circ} \mathrm{C}$ and $50 \mathrm{C}$. All these parameters were converted into data and fluently incorporated into the ANSYS for the validation processes to be set.

\subsection{Meshing and Geometry}

In this analysis, the geometry of the project was created by AUTOCA software. The mesh was created using mechanical ANSYS. In the complex meshed model, tri type pave mesh was used and quad type was used in the remaining meshed model [13]. ANSYS has a completed mesh as seen in Figure 1. The schematic diagram below depicts a rectangular tube with a height of $31 \mathrm{~cm}$ and a width of $2 \mathrm{~cm}$ and a thickness of $0.3 \mathrm{~cm}$.

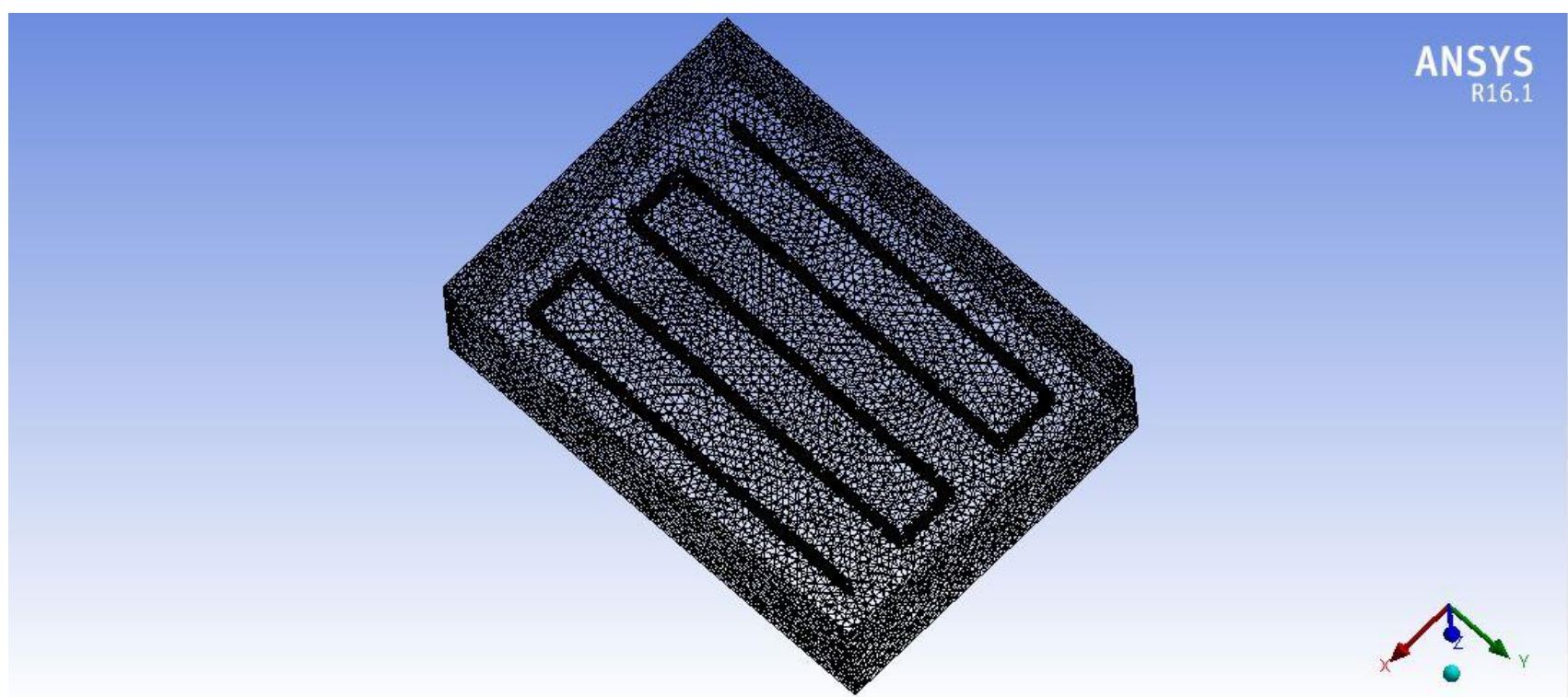

Fig. 1. The meshed model of the car radiator

\section{Results and Discussion}

\subsection{Grid Independent Test}

In the $\mathrm{RE}=15000$ study, mesh was considered to be set with a $\mathrm{T}=45 \mathrm{C}$. It is shown that, depending on the results, the $\mathrm{Nu}$ is equal to the number of faces, and when the number of faces was 150,000, the Nu was 90. Moreover, as the number of faces increases to 160000 and up, there is no change in $\mathrm{Nu} .160000$ faces were thus programmed to conduct the simulation process as shown in Figure 2 . 


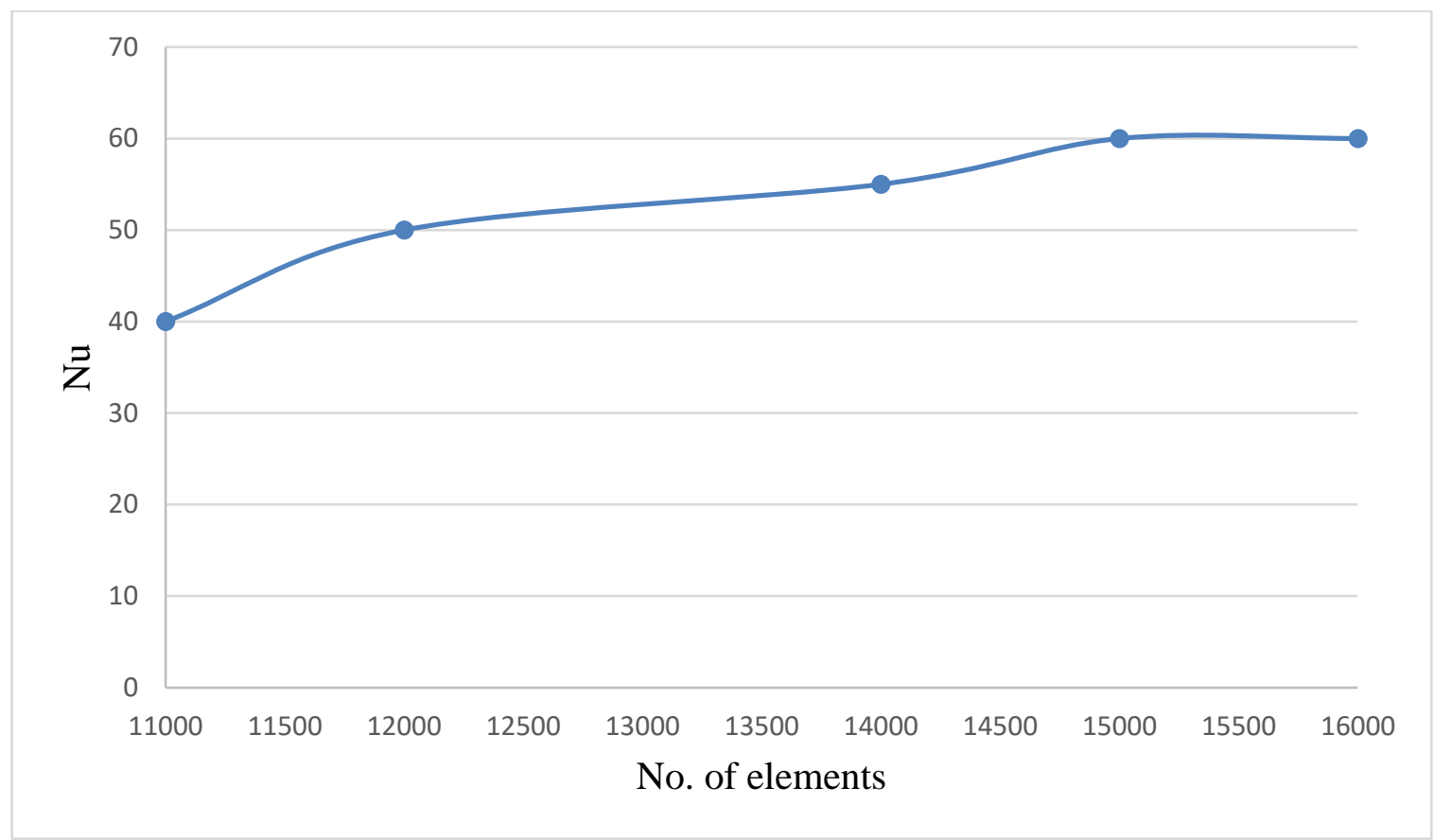

Fig. 2. Grid independent test of the current geometry

\subsection{Validation}

Code validation is one of the important steps taken in numerical studies to ensure that the numerical codes are accurate as in other previous studies. The code validation process also helps to test the code for running. The code validation process used in [14] was used for code validation purposes in this report. In the application of the car radiator, this group of researchers numerically investigated the effect of nano particles in the implementation of heat transfer. The findings of the comparison carried out in this study between the results of the current study and those $[15,16]$ have been contrasted with the experimental similarity of the numerical evidence collected in the present investigation [17].

Figure $3(a)$ and $3(b)$ compare the experimental results with the prediction of the number of nanofluids in Nusselt. The relation between the flow rate and the Nusselt number at temperature 45 ${ }^{\circ} \mathrm{C}$ at $1 \%$ nano particle concentration is seen in Figure 1 . While the relation between the flow rate and the Nusselt number at temperature $45^{\circ} \mathrm{C}$ is seen in Figure 2 at 0.7 percent nano particle concertation. In these two numbers, strong consensus can be seen $[18,19]$. The computation of the absolute average error shows 7 percent to be the water-based nanofluid prediction error. 


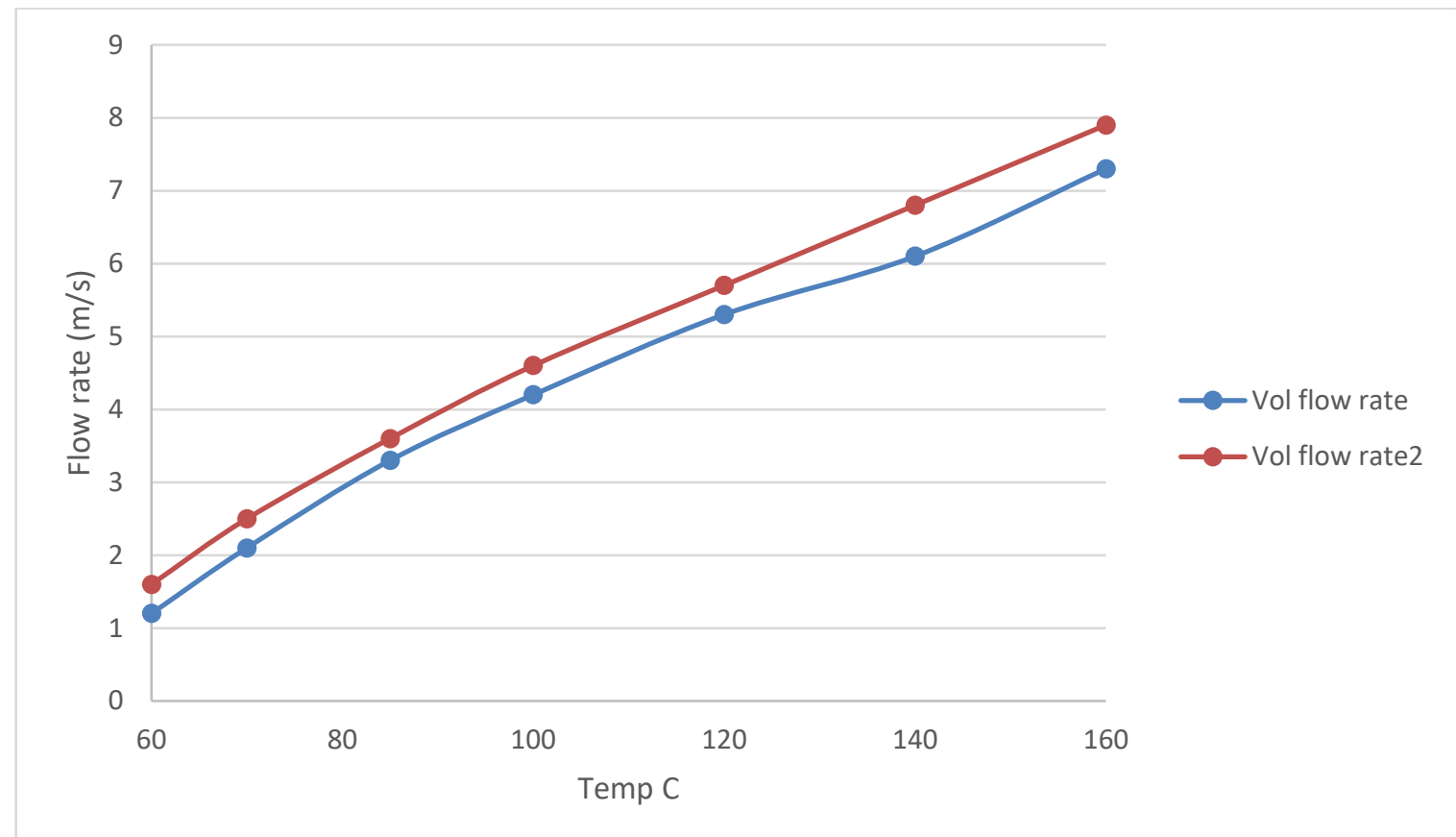

Fig. 3(a). Validation of the temperature with flow at concertation $1 \%$

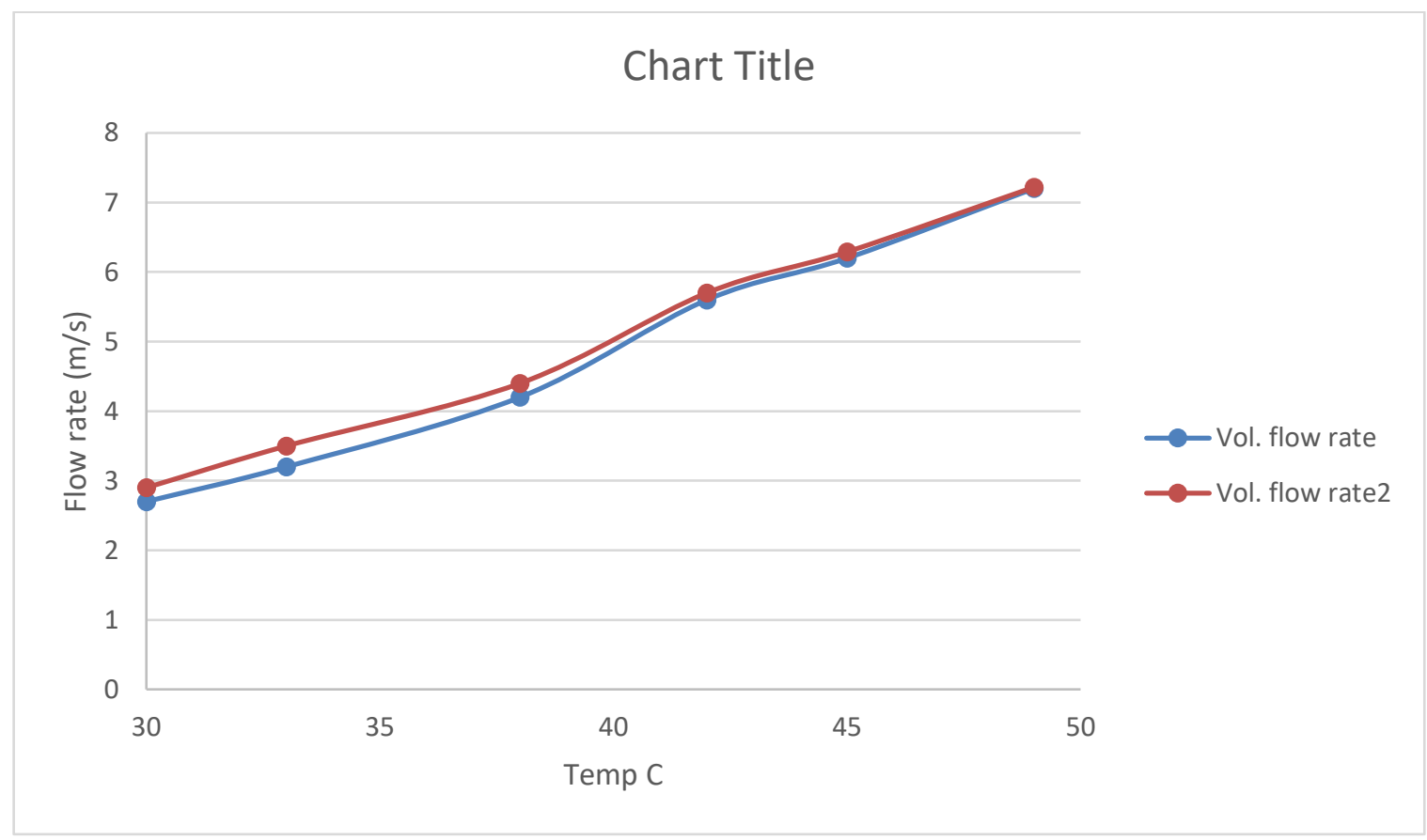

Fig. 3(b). validation of the temperature with flow Concertation 0.7

\subsection{Heat Transfer to Pure Water}

A number of studies with purity of water and pure EG were performed before the tests on nanofluids as a coolant for the car radiator, in order to verify the efficiency and accuracy of the experimental system. Figure 4 and 5 illustrates the experimental effects of water flow at a steady inlet temperature of $50^{\circ} \mathrm{C}$ through the radiator. The higher Reynolds number is shown to increase pure water's heat transfer coefficient. The experimental data are contrasted with the following empirical association proposed in turbulent flow. 


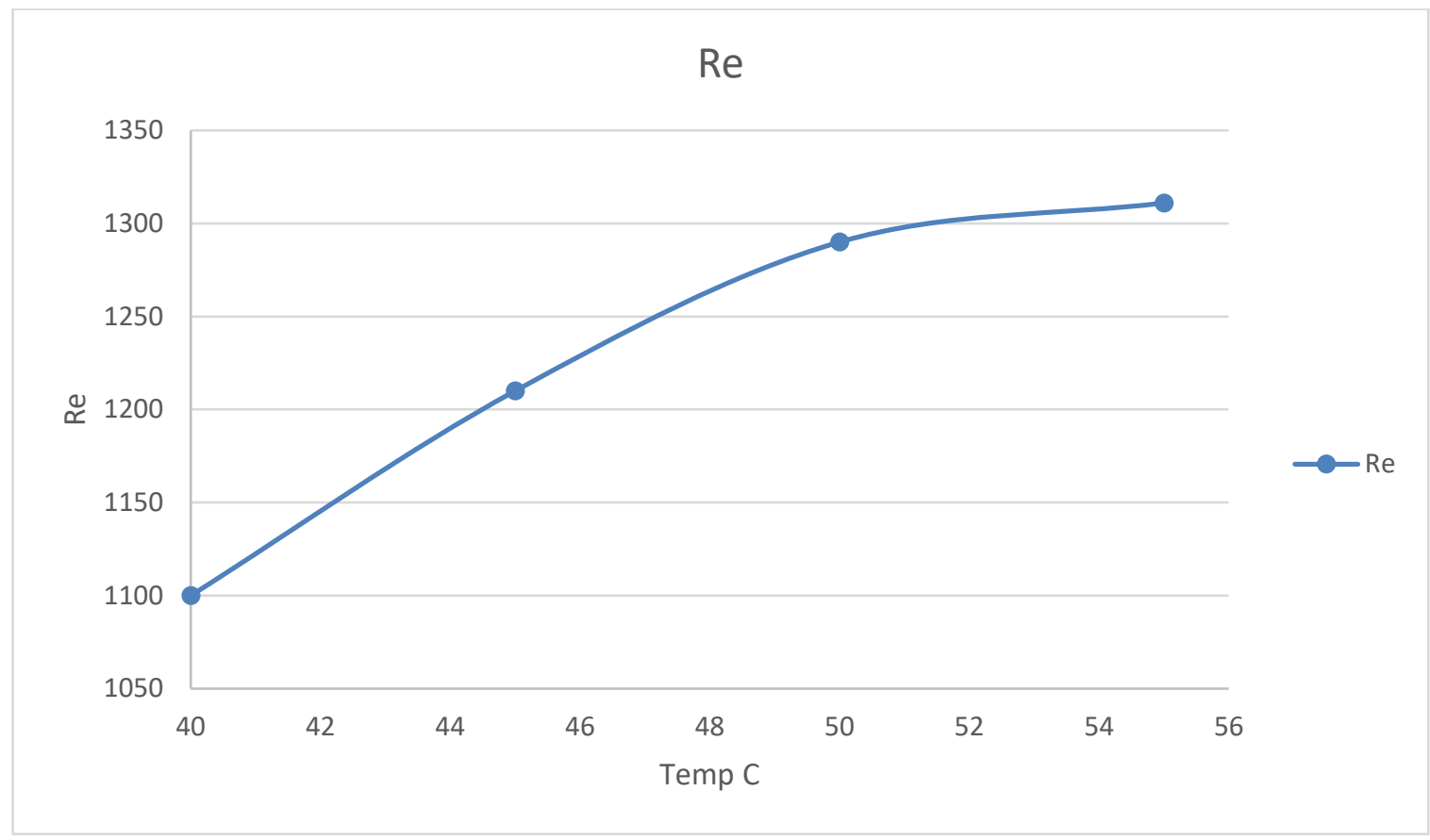

Fig. 4. Temperature with Reynolds number

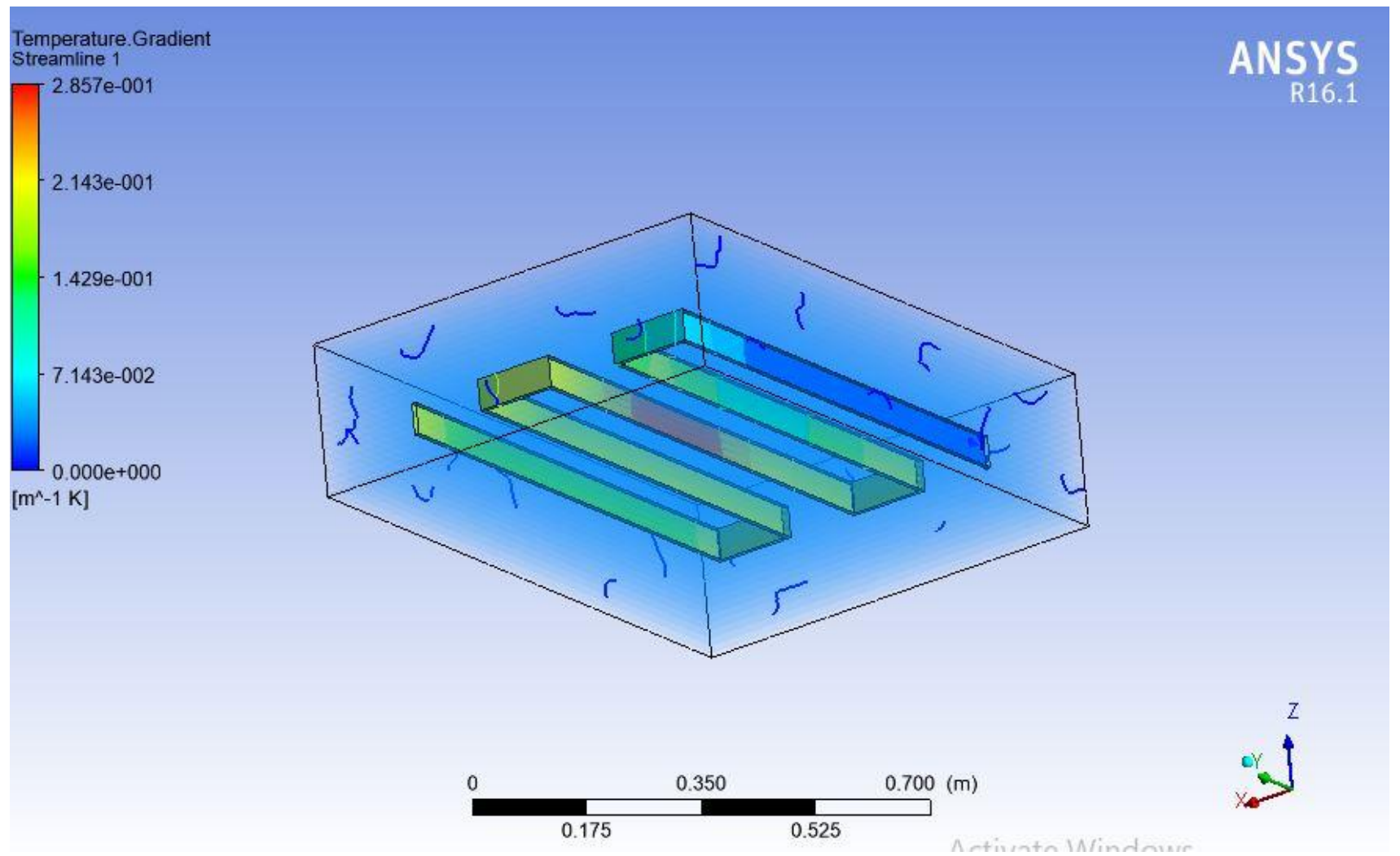

Fig. 5. Simulation heat transfer at $70 \mathrm{c}$ between environment and radiator

\subsection{Water-Based Heat Transfer Nanofluids}

Nanofluid is added at different $\mathrm{Al}_{2} \mathrm{O}_{3}$ levels, i.e., $0.1,0.3,0.5,0.7$, and 1 vol. Percent and at set temperature. In order to understand the impact of the temperature on the thermal efficiency of the radiator, various inlet temperatures for each concentration have been added. Temperatures include 70 for water-based nanofluids and $70{ }^{\circ} \mathrm{C}$ for EG-based nanofluids. Figure 6 demonstrate the 
improvement of heat transfer as the traditional coolant by water- and EG-dependent nanofluids due to substitution of water. Through raising the nano fluid concertation to 1 vol. percent of the water's Al2O3 nanoparticle. The number of the Nusselt is increased. The mean number of Nusselt at $70{ }^{\circ} \mathrm{C}$ with a 1 percent maximum concentration is 65 and the minimum number of Nusselt at a minimum nano fluid concentration is 65 .

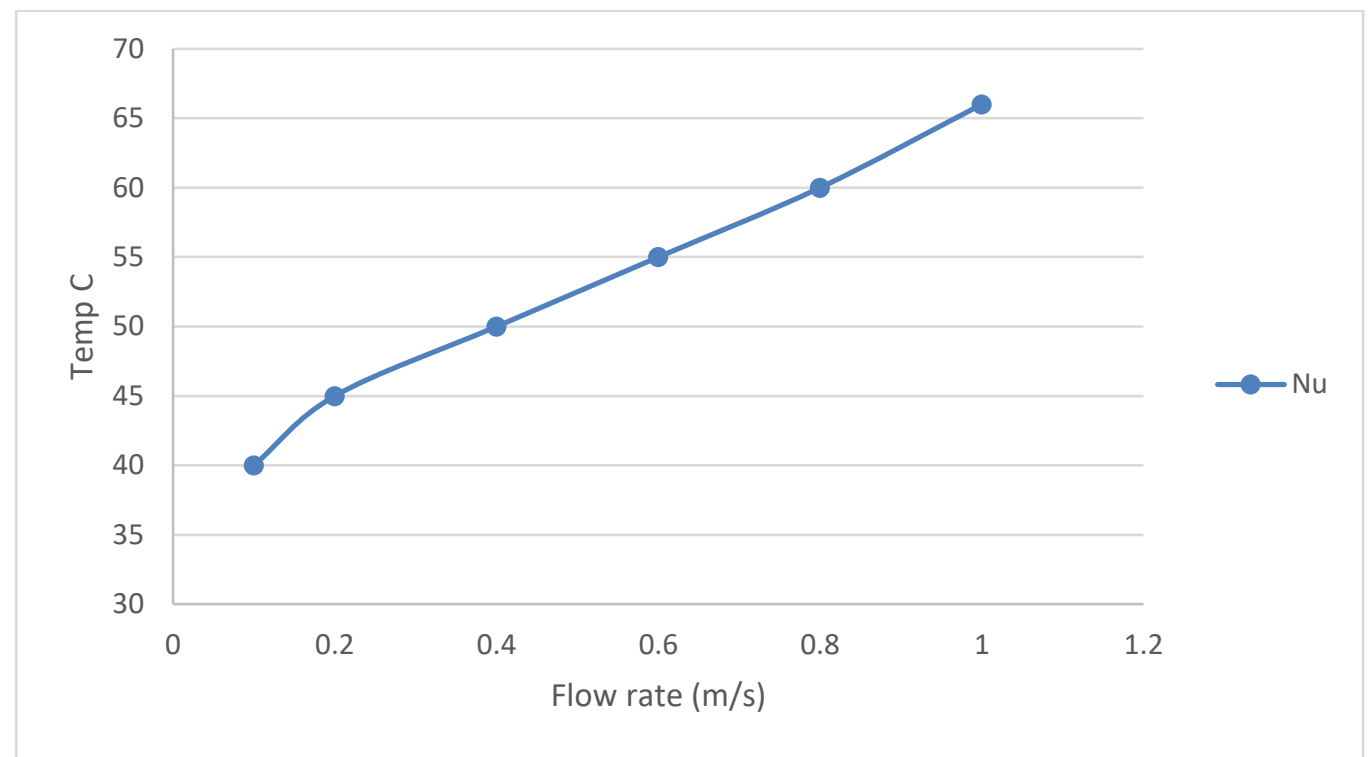

Fig. 6. Flow rate with temperature at Nu 65

This process leads to small quantities of Al2O3 nanoparticles that are being added to the basis liquid, an improvement in density and thermal conductivity, while on the other hand, Viscosity increases more dramatically than the base fluid as shown in Figure 7.

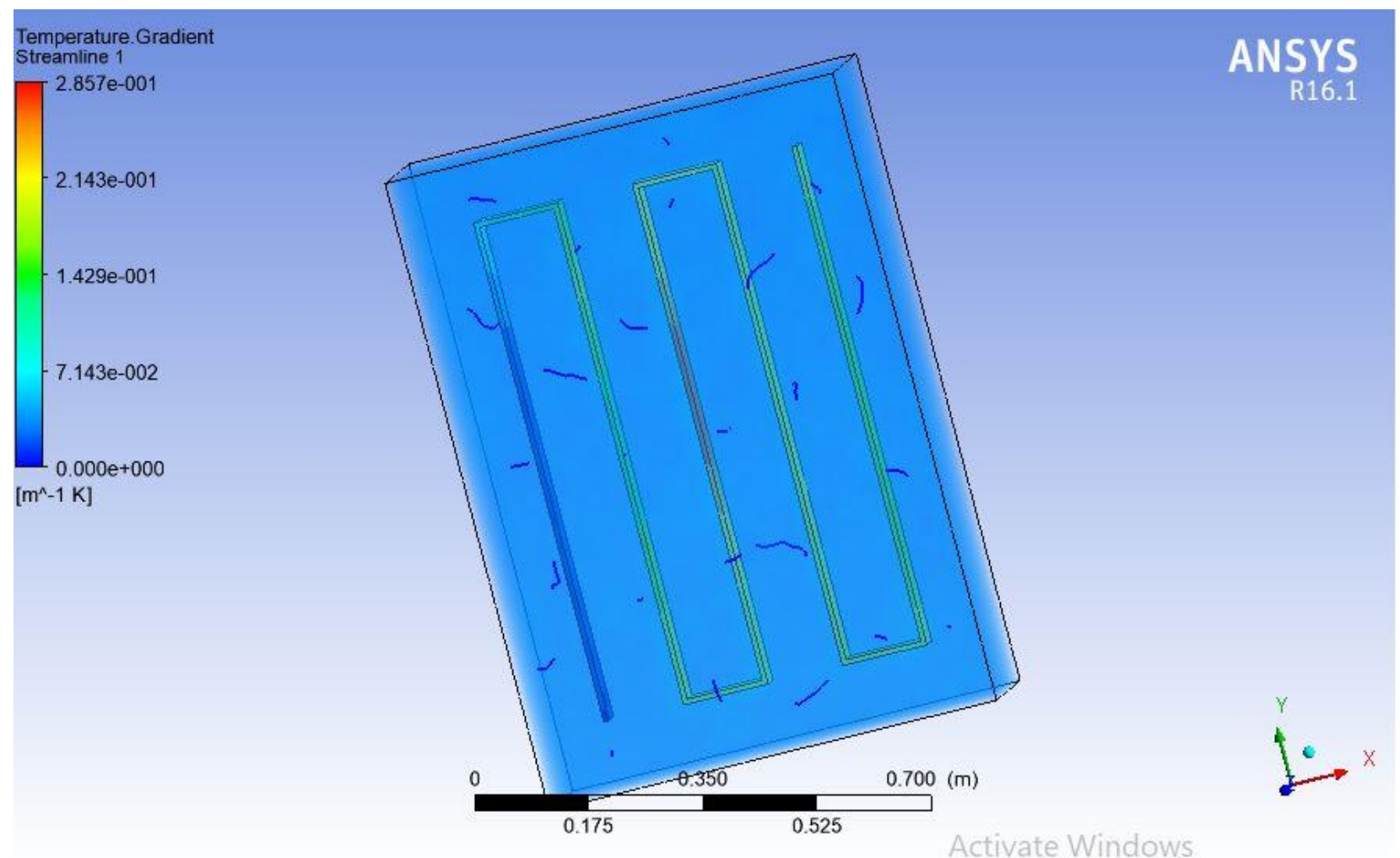

Fig. 7. Simulation of heat transfer at Nu 65 
The combination of water in different quantities depending on the geographical weather is a traditional fluid commonly used in the car radiator. Based on the outcomes, there are three separate amounts of 5, 10 and 20 volts of water / EC binary mixtures. Where the results have shown that the percentage EG was prepared as basic fluids to provide additional guidance on the impact of the addition of nanoparticles to the radiator coolant as shown in Figure 8.

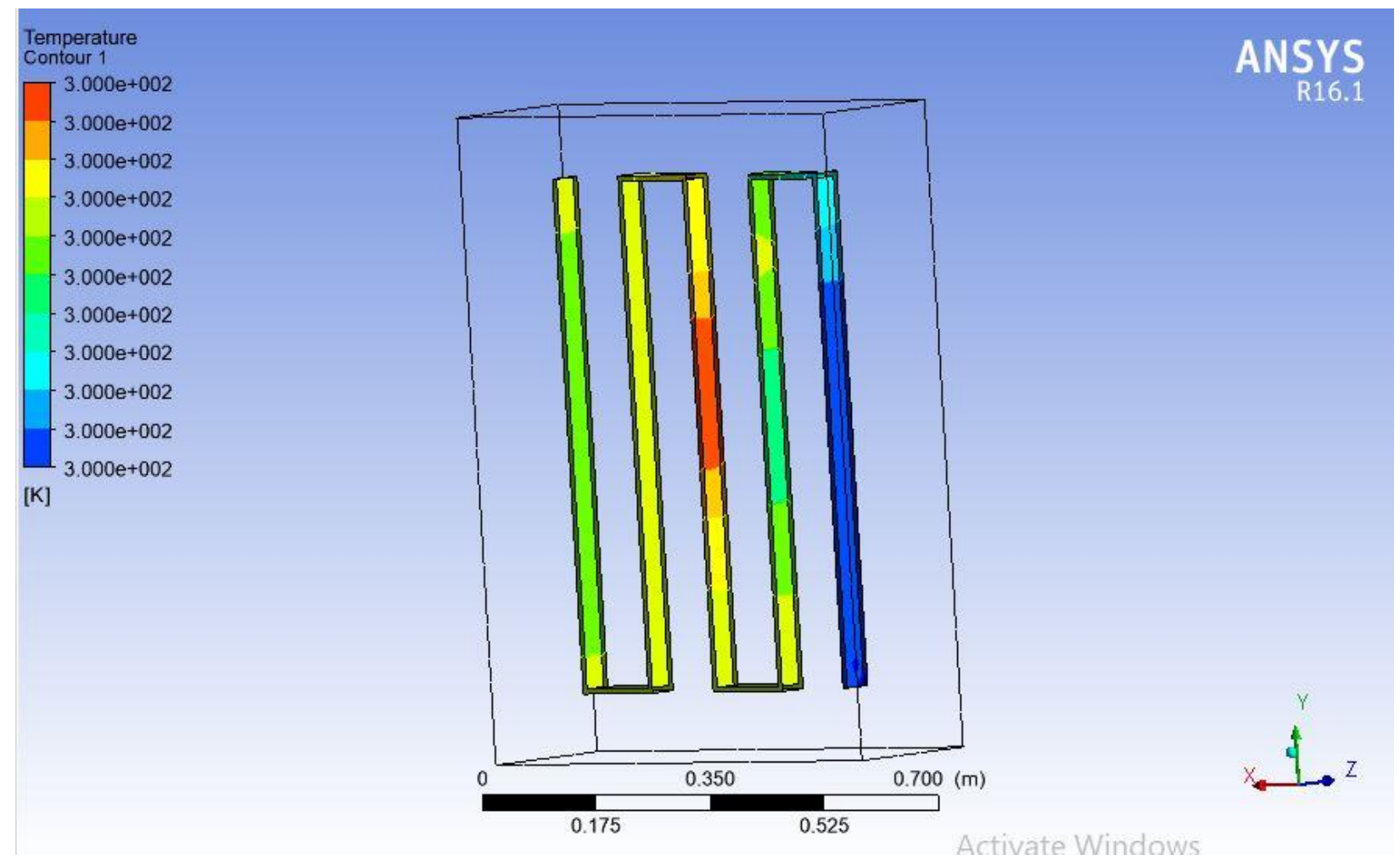

Fig. 8. Simulation of heat transfer at 20 vol.\% EG

\section{Conclusion}

Using nanofluid, heat transfer in the car radiator was numerically observed. In order to simulate heat transfer across water and water-based nano particles and the medium, ANSYSY fluent was used. This analysis has been confirmed with experimental findings and, when adding the same boundary condition, the error was 8 percent dependent on the simulation results. The sum of Nusselt was increased by increasing the concertation of the nano particles dependent on the results of numerical analysis. The increase in the Nusselt number leads to the heat exchanger 's enactment. Previous experimental data have shown that the heat transfer of nanofluids depends heavily on the concentration and flow conditions and is weakly temperature dependent, thus calculating the flow and concentration of nano particles for thermal transfer conduct in the present study.

\section{References}

[1] Akbarzade, S., K. Sedighi, and M. Farhadi. "Experimental investigation of force convection heat transfer in a car radiator filled with SiO2-water nanofluid." International Journal of Engineering 27, no. 2 (2014): 333-340. https://doi.org/10.5829/idosi.ije.2014.27.02b.17

[2] Ali, Hafiz Muhammad, Hassan Ali, Hassan Liaquat, Hafiz Talha Bin Maqsood, and Malik Ahmed Nadir. "Experimental investigation of convective heat transfer augmentation for car radiator using ZnO-water nanofluids." Energy 84 (2015): 317-324. https://doi.org/10.1016/j.energy.2015.02.103 
[3] Ali, Hafiz Muhammad, Muhammad Danish Azhar, Musab Saleem, Qazi Samie Saeed, and Ahmed Saieed. "Heat transfer enhancement of car radiator using aqua based magnesium oxide nanofluids." Thermal science 19, no. 6 (2015): 2039-2048. https://doi.org/10.2298/TSCI150526130A

[4] Delavari, Vahid, and Seyed Hassan Hashemabadi. "CFD simulation of heat transfer enhancement of Al2O3/water and Al203/ethylene glycol nanofluids in a car radiator." Applied thermal engineering 73, no. 1 (2014): $380-390$. https://doi.org/10.1016/i.applthermaleng.2014.07.061

[5] Leong, K. Y., Rahman Saidur, S. N. Kazi, and A. H. Mamun. "Performance investigation of an automotive car radiator operated with nanofluid-based coolants (nanofluid as a coolant in a radiator)." Applied Thermal Engineering 30, no. 17-18 (2010): 2685-2692. https://doi.org/10.1016/i.applthermaleng.2010.07.019

[6] Goudarzi, K., and H. Jamali. "Heat transfer enhancement of Al2O3-EG nanofluid in a car radiator with wire coil inserts." Applied Thermal Engineering $118 \quad$ (2017): https://doi.org/10.1016/i.applthermaleng.2017.03.016

[7] kadhim Sharaf, Hussein, Nawal Aswan Abdul Jalil, and Sadeq Salman. "A simulation on the effect of ultrasonic vibration on ultrasonic assisted soldering of $\mathrm{Cu} / \mathrm{SAC} 305 / \mathrm{Cu}$ joint." Journal of Advanced Research in Applied Mechanics 36, no. 1 (2017): 1-9.

[8] Naraki, M., S. M. Peyghambarzadeh, S. H. Hashemabadi, and Y. Vermahmoudi. "Parametric study of overall heat transfer coefficient of CuO/water nanofluids in a car radiator." International Journal of Thermal Sciences 66 (2013): 82-90. https://doi.org/10.1016/j.ijthermalsci.2012.11.013

[9] Subhedar, Dattatraya G., Bharat M. Ramani, and Akhilesh Gupta. "Experimental investigation of heat transfer potential of Al2O3/Water-Mono Ethylene Glycol nanofluids as a car radiator coolant." Case studies in thermal engineering 11 (2018): 26-34. https://doi.org/10.1016/i.csite.2017.11.009

[10] Sharaf, Hussein Kadhim, M. R. Ishak, S. M. Sapuan, and N. Yidris. "Conceptual design of the cross-arm for the application in the transmission towers by using TRIZ-morphological chart-ANP methods." Journal of Materials Research and Technology 9, no. 4 (2020): 9182-9188. https://doi.org/10.1016/i.jmrt.2020.05.129

[11] Sharaf, Hussein Kadhim, M. R. Ishak, S. M. Sapuan, N. Yidris, and Arash Fattahi. "Experimental and numerical investigation of the mechanical behavior of full-scale wooden cross arm in the transmission towers in terms of loaddeflection test." Journal of Materials Research and Technology 9, no. 4 (2020): 7937-7946. https://doi.org/10.1016/i.jmrt.2020.04.069

[12] Sharaf, Hussein Kadhim, Sadeq Salman, Marwah H. Abdulateef, Rustem R. Magizov, Vasilii Ivanovich Troitskii, Zaid Hameed Mahmoud, Rafis H. Mukhutdinov, and Harsha Mohanty. "Role of initial stored energy on hydrogen microalloying of ZrCoAl (Nb) bulk metallic glasses." Applied Physics A 127, no. 1 (2021): 1-7. https://doi.org/10.1007/s00339-020-04191-0

[13] Sharaf, Hussein Kadhim, Sadeq Salman, Mohammad Hassan Dindarloo, Valery I. Kondrashchenko, Alla Andronikovna Davidyants, and Sergey V. Kuznetsov. "The effects of the viscosity and density on the natural frequency of the cylindrical nanoshells conveying viscous fluid." The European Physical Journal Plus 136, no. 1 (2021): 1-19. https://doi.org/10.1140/epip/s13360-020-01026-y

[14] Peyghambarzadeh, S. M., S. H. Hashemabadi, S. M. Hoseini, and M. Seifi Jamnani. "Experimental study of heat transfer enhancement using water/ethylene glycol based nanofluids as a new coolant for car radiators." International communications in heat and mass transfer 38, no. 9 (2011): 1283-1290. https://doi.org/10.1016/j.icheatmasstransfer.2011.07.001

[15] Oliveira, Guilherme Azevedo, Edwin Martin Cardenas Contreras, and Enio Pedone Bandarra Filho. "Experimental study on the heat transfer of MWCNT/water nanofluid flowing in a car radiator." Applied Thermal Engineering 111 (2017): 1450-1456. https://doi.org/10.1016/i.applthermaleng.2016.05.086

[16] kadhim Sharaf, Hussein, Nawal Aswan Abdul Jalil, and Sadeq Salman. "A simulation on the effect of ultrasonic vibration on ultrasonic assisted soldering of $\mathrm{Cu} / \mathrm{SAC} 305 / \mathrm{Cu}$ joint." Journal of Advanced Research in Applied Mechanics 36, no. 1 (2017): 1-9.

[17] Ashham, M. "Simulation of Heat Transfer in a Heat Exchanger Tube with Inclined Vortex Rings Inserts." International Journal of Applied Engineering 12, no. 20 (2017): 9605-9613.

[18] Abd El-Hameed, Afaf M., and Y. A. Abdel-Aziz. "Aluminium Alloys in Space Applications: A Short Report." Journal of Advanced Research in Applied Sciences and Engineering Technology 22, no. 1 (2021): 1-7.

[19] Zulkurnai, Fatin Farhanah, Wan Mohd Faizal Wan Mahmood, Norhidayah Mat Taib, and Mohd Radzi Abu Mansor. "Simulation of Combustion Process of Diesel and Ethanol Fuel in Reactivity Controlled Compression Ignition Engine." CFD Letters 13, no. 2 (2021): 1-11. https://doi.org/10.37934/cfdl.13.2.111 